\title{
Beliefs about Medicine and Antihypertensive Medication Adherence among Patients' Attending a County Referral Hospital in Kenya
}

\author{
S. O. Otenyo and D. K. Kereri
}

\section{ABSTRACT}

Background: Non-adherence with antihypertensive medication and lifestyle recommendations remains a serious problem in many developed and developing countries. Patient's belief about medication has been consistently found to be a significant predictor of medication adherence in various studies.

Objective: To assess the relationship between hypertension medication beliefs and adherence to hypertension medication among patients attending a county referral hospital in Kenya.

Methods: A Quantitative research design, utilizing a simple random sampling method and a researcher administered structured questionnaire was adapted. Previously validated, Beliefs about Medication Questionnaire (BMQ) and the Morisky's Medication Adherence Scale (MMAS-4) were utilized. Bivariate analysis was conducted using Chi square test and the Mann Whitney $U$ test while multivariate data analysis was conducted using Binary logistic regression analysis. Odds ratio and $\mathbf{9 5} \%$ confidence intervals were calculated. Results with $\mathrm{p}$ values $\leq \mathbf{0 . 0 5}$ were considered statistically significant.

Results: Data from 96 participants, 55\% female and $58 \%$ being over the age of 65 years were analyzed. $33.3 \%$ of the respondents had a high adherence level. None of the socio-demographic variables were found to be statistically significant to medication adherence using Chi square test analysis. Patients who had lower scores of concerns about medication were more likely to be adherents than their counter parts $p=0.001(O R=1.047$; CI (1.019-1.076) likewise lower scores of general overuses predicted medication adherence $p=0.001(O R=1.069 ; C I=1.026-1.114)$.

Conclusion: Health workers should formulate interventions to reduce concerns regarding medication, in order to promote adherence as informed by the findings of this study.

Keywords: Adherence, Hypertension, Antihypertensive, Beliefs about Medication.

\section{INTRODUCTION}

Blood pressure control through pharmacological treatment leads to major benefits in the prevention of mortality and morbidity from cardiovascular complications [1]. Optimal control of blood pressure has been reported to reduce the incidence of stroke by an average of $35-40 \%$, myocardial infarction by $20-25 \%$ and heart failure by $>50 \%$. According to world health organization adherence is the extent to which a person's behavior of taking medication corresponds with agreed recommendations from a healthcare provider [2].

Nonadherence with antihypertensive medications and lifestyle recommendations remain a serious problem in many developed and developing countries [3]. It is projected that
Published Online: June 21, 2021

ISSN: $2736-5476$

DOI: 10.24018 /ejclinicmed.2021.2.3.56

S. O. Otenyo*

Egerton University, Nakuru, Kenya.

(e-mail: salome.otenyo@egerton.ac.ke)

D. K. Kereri

Egerton University, Nakuru, Kenya.

(e-mail: deborah.kereri@egerton.ac.ke)

*Corresponding Author about $70 \%$ of patients on antihypertensive medications do not take them as prescribed [4]. Nonadherence results to poor health outcomes and increased medical costs of drug-related morbidity [5]. In Kenya a descriptive cross-sectional study undertaken at Kenyatta National Hospital to determine adequacy of blood pressure control and level of adherence with antihypertensive therapy, adherence level was found to be $31.8 \%$ [9].

The non-adherence practice maybe particularly higher in developing countries where there is poor accessibility to medicines and healthcare services. There is also low level of awareness about the lifelong nature of hypertension management among patients [7]. This is as a result of complex interplay between patient, healthcare providers and 
socioeconomic factors. Patients' beliefs about medication have been consistently found to be a significant predictor of medication adherence in various studies [13]. A study among patients with chronic illness found that their beliefs about medication predicted patient's adherence to medication more strongly than either clinical or socio-demographic factors [26].

In order to have a complete picture of medication adherence, the patient's medication beliefs must be taken into consideration [13]. Stronger perception of specific-necessity to use drug to maintain health with lower specific-concerns about adverse effects of drug consumption and low perspective of general harm of drugs as being addictive and toxic substances with low perception of general overuse opinions in terms of drug prescription was found to be significantly related to medication adherence [27].

Focusing on the aspect of uncontrolled blood pressure, the study explored aspects of how medication beliefs affect adherence to hypertensive medication regimen, as part of how to ensure effective hypertension control among patients. A better understanding of patients' beliefs about medication may enable health workers to develop interventions that aim to correct misconceptions and improve clinical outcomes of hypertension patients.

\section{DESCRIPTION OF THE SURVEY AND THE STUDY POPULATION}

A descriptive quantitative cross-sectional survey was adopted, including 100 hypertensive patients who were seen at the Nakuru County Referral Hospital hypertension outpatient clinic. There were 300 hypertensive patients registered at the outpatient clinic, who are given an appointment every month. The clinic operates once every week and an average of 80 patients attend weekly. Due to impracticability of selecting every hypertensive patient visiting the facility, the study adopted a sample using the Yamane Model [28] to get the study respondents.

$$
n=\frac{N}{1+N\left(e^{2}\right)}
$$

So, the sample size was 100 respondents, this will enable the researcher to have at least a response rate of 50\% using power calculation. The respondents were then selected using simple random sampling technique using patients register at the Nakuru County Referral Hospital hypertension outpatient clinic as the sampling frame. The researcher approached the identified patients during their appointment days and explained to them that they had been selected to participate in a study. Each of the participants was then informed about the study, its objectives, and the method of data collection.

The patients were then given the participants information sheet and allowed to go home with it, so that they could read through it again before they decide to participate in the study. They would then inform the researcher of their decision during their next appointment, the patients who inform the researcher of their willingness to participate in the study would be given time to see their clinician and get their medication refill before being interviewed.

The researcher utilized a structured questionnaire which compromised previously validated belief about medication questionnaire [7] and the four item Morisky's medication adherence questionnaire [8]. Ethical clearance was sought from university of Dundee ethical review board and the ethical committee of the Nakuru County Referral Hospital before study commenced.

\section{DATA ANALYSIS}

Data was screened and cleaned to ensure accurate data entry. Statistical data analysis was then done using SPSS software program version 20. Descriptive analysis was carried out and categorical data were expressed as mean, standard deviation, frequency, and percentages. Associations between demographic variables and level of adherence were tested using Pearson's Chi Square test while associations between beliefs about medication questionnaire items and medication adherence level were assessed with MannWhitney $\mathrm{U}$ test. Binary logistic regression was conducted using variables that showed a $\mathrm{p}$ value $\leq 0.05$ in univariate analysis. Statistical significance for all the analyses was set to be $\mathrm{p} \leq 0.05$.

\section{RESUlTS}

\section{A. Socio-demographic Characteristics}

A total of $33.3 \%(n=32)$ had a high adherence while $66.7 \%$ $(\mathrm{n}=64)$ had low adherence. Univariate analysis was done using Chi square test to determine the relationship between high and low adherence with individual socio-demographic variables. The results showed that there were no significant relationships between socio-demographic variables and adherence (Table I).

\begin{tabular}{|c|c|}
\hline Variable & Total $(\mathrm{n}=96), \%$ \\
\hline \multicolumn{2}{|l|}{ Age (years) } \\
\hline$<65$ & $40(42)$ \\
\hline$\geq 65$ & $56(58)$ \\
\hline \multicolumn{2}{|l|}{ Gender } \\
\hline Male & $43(45)$ \\
\hline Female & $53(55)$ \\
\hline \multicolumn{2}{|l|}{ Marital status } \\
\hline Married & $63(66)$ \\
\hline Single/divorced & $33(34)$ \\
\hline \multicolumn{2}{|l|}{ Education level } \\
\hline$<$ secondary education & $72(75)$ \\
\hline$\geq$ secondary education & $24(25)$ \\
\hline \multicolumn{2}{|l|}{ Occupation } \\
\hline Government employed & $37(39)$ \\
\hline Self/unemployed & $59(62)$ \\
\hline
\end{tabular}

\section{B. Participants Beliefs about Medication}

Individuals with stronger Specific Concerns about their medicines tend to be more skeptical of them and thus, more non adherent. While individuals with a strong SpecificNecessity beliefs translate into them having a higher medication adherence [14]. The General Harm score signifies the degree of an individual's beliefs that his or her medicines are harmful; therefore, a lower General Harm score means 
higher medication adherence. The General Overuse scores signify the degree of an individual's belief that his or her physician overprescribes medication; therefore, a lower General Overuse score means higher medication adherence. The results showed that the participants had a higher concern about their medication Specific-Concern scale mean of 15.58 (2.98) followed by a high necessity of their medication, Specific- Necessity scale with a mean of 13.39(2.98) and they had very low belief of medication overuse, General-Overuse scale mean of 10.18(1.79) (Table II).

TABLE II: MEAN SCORES FOR BELIEFS ABOUT MEDICINE QUESTIONNAIRE

\begin{tabular}{ccc}
\hline Scale & Mean & Standard deviation \\
\hline Specific-Necessity & 13.39 & 2.98 \\
Specific-Concern & 15.58 & 2.98 \\
General-Harm & 10.23 & 1.98 \\
General-Overuse & 10.18 & 1.79 \\
\hline
\end{tabular}

When adherent groups were arranged according to their responses to the Beliefs about Medication Questionnaire, there was evidence of a difference between participants' scores in the Specific-Concern and General-Overuse subscale. In relation to the Specific- Concern subscale, and compared to the high adherence group, mean scores were higher in the low adherence group for the items which states that the patients had more concerns about taking the medications (Mean of adherence level; Low $=50.27$, High=44.97; $\mathrm{z}=-0.480 ; \mathrm{p}=<0.001)$. The same pattern, higher mean scores in the low adherence relative to the high adherence, was observed in the General-Overuse subscale (Mean of adherence level; Low $=50.27$, High=44.95; $\mathrm{z}=-0.751 ; \mathrm{p}=0.041)$ (Table III).

TABLE III: BELIEF ABOUT MEDICATION BY ADHERENCE LEVEL

\begin{tabular}{ccccc}
\hline & Adherence & Level & & \\
\cline { 2 - 3 } BMQ Scale & $\begin{array}{c}\text { Low } \\
\text { adherence }\end{array}$ & $\begin{array}{c}\text { High } \\
\text { adherence }\end{array}$ & \multirow{2}{*}{ z scores } & p-value \\
\cline { 2 - 3 } & Mean & Rank & & \\
\cline { 2 - 3 } Specific-Necessity & 49.45 & 46.59 & -0.887 & 0.375 \\
Specific-Concerns & 50.27 & 44.97 & -0.480 & $<0.001$ \\
General-Harm & 49.55 & 46.41 & -0.529 & 0.597 \\
General-Overuse & 50.27 & 44.95 & -0.751 & 0.041 \\
\hline
\end{tabular}

\section{Independent Factors Associated with Adherence}

In multivariate analysis, using Binary logistic regression to analyze the impact of Medication Beliefs on adherence, weaker beliefs of Specific-Concerns about medication were related to having high adherence to antihypertensive medication (odds ratio: 1.047, $\mathrm{p}=0.001$; C.I (1.019-1.076). Likewise weaker beliefs of General-Overuse of the medication were related to having high adherence to antihypertensive medication (odds ratio: $1.069, \mathrm{p}=0.001$; C.I (1.026-1.114) (Table IV).

TABLE IV: INDEPENDENT FACTORS ASSOCIATED WITH ADHERENCE

\begin{tabular}{cccccccc}
\hline Statement & $\beta$ & S. E & $\begin{array}{c}\text { Wald } \\
\text { Test }\end{array}$ & $\begin{array}{c}\text { p- } \\
\text { value }\end{array}$ & $\begin{array}{c}\text { Odds } \\
\text { Ratio } \\
\text { (O.R) }\end{array}$ & Lower & Upper \\
\hline $\begin{array}{c}\text { Specific- } \\
\begin{array}{c}\text { Concerns } \\
\text { General- } \\
\text { Overuse }\end{array}\end{array}$ & 0.046 & 0.014 & 10.971 & 0.001 & 1.047 & 1.019 & 1.076 \\
\hline
\end{tabular}

\section{DISCUSSION}

\section{A. Adherence to Antihypertensive Medication}

The results showed that majority of the respondents exhibited low adherence $(66.7 \%)$ while only a handful of respondents exhibited high adherence (33.3\%). The proportion of patients with high adherence was too low for this population bearing in mind that the patients were already diagnosed, started on hypertensive medication, and visiting a health care facility; these rates indicate a significant problem given all the known complications that are related to uncontrolled hypertension. In a study done in a Referral hospital in Central Kenya, only $33.4 \%$ of patients attending Outpatient hypertension clinic had their blood pressure within the recommended limits [10], this could be a reflection of patients in this region not adhering to their prescribed hypertension medication thus making them have uncontrolled blood pressure.

The results were similar to those reported at Kenyatta National Hospital Hypertension outpatient clinic [9], where only $31.8 \%$ of the patients had high adherence. However other studies found a higher adherence rate of $69 \%, 63 \%$, and $53.3 \%$ [11-13]. These variations could be due to patient's socio-demographic characteristics of the various countries, adherence measurement tool that was used, study design, study population and patient's self -care behavior.

\section{B. Socio-demographic Factors and Antihypertensive Medication Adherence}

Socio-demographic variables (age, gender, marital status, educational level, and occupation) in this study were found not to be significantly associated with medication adherence. These results were inconsistent with other studies that found socio-demographic variables to be associated with adherence. A study found patients with advanced age to being associated with good adherence to antihypertensive medication, and they attributed the findings to older people having comorbidities that make them perceive hypertension as severe and hence adhere better to antihypertensive medication regimen [14].

Also, a study done in Dar es Saalam found females to being significantly more adhering than males [15]. While patients with higher education level were found to have higher adherence, this was attributed to patients with higher education level able to read their medication instruction and being able to comprehend instructions from the doctor [16].

Additionally, a study found patients who are nonemployed to be better adherers than their employed counterparts [17]. These differences in findings may be attributed to cultural differences as well as different methods that were used to measure adherence.

\section{Belief about Medicine and Medication Adherence}

Specific concerns about medication were found to be significantly associated with anti-hypertensive medication, patients who had less concerns about their hypertensive medication regimen were more adherent to their antihypertensive medication. Alike [18]-[22] found that higher concerns about medicine were related to poorer antihypertensive medication adherence.

Specific necessity about medicine was found not to be statistically related to medication adherence. This means that 
in this study the patients' perception of their treatment as necessary did not relate with their adherence to prescribed medication regimen. This was different from studies done by [20]-[23] who found Specific necessity to be statistically associated with medication adherence. This difference could be because of the different settings which could result in different cultural beliefs of the patients.

Beliefs of general harm were not significantly related to medication adherence. This means that patients' perception of the side effects of their medication did not relate with adherence to their recommended medication. However [20], [22], [24] found that patients who had low adherence levels had strong beliefs of medication as harmful. This difference could be due to patient's knowledge of side effects.

General overuse was found to be statistically significant in predicting adherence, whereby low beliefs of overuse projected high adherence to antihypertensive medication. This could mean that these patients had strong beliefs in their clinicians and the care they get from them. Conversely [20], [23], [24] did not find a significant relationship between general overuse and medication adherence.

\section{STUDY LiMITATION}

The potential to generalize the study findings is limited due to the use of only one study site thus only patients who attended the outpatient hypertensive clinic and were also willing to take part in the study were included. Although this study used well-validated questionnaires, the use of selfreport data is a possible limitation because self-reported data are subject to recall bias. However, the participants were encouraged to be accurate in reporting the information during data collection.

By selecting the participants in a hospital setting, the results of this study may overestimate the rate of adherence as all participants do have a higher degree of awareness of their hypertension condition compared to the general population. Since this was a cross-sectional study, it could not show causative relationship between illness representations, medication beliefs and adherence to medication.

\section{CONCLUSION}

In this study, specific concerns and general overuse were found to be significantly related to medication adherence. To increase generalizability of the findings, further studies should have a larger sample size with multiple study sites. Qualitative studies can also be done to have an in-depth exploration of how the various beliefs, illness perception affect adherence.

\section{WHAT IS ALREADY KNOWN ON THIS TOPIC?}

- Patients with hypertension do have a problem to adherence to their medication regimen, and it is often associated with the long-term therapy.

- Beliefs about medication determine if the patient will adhere or not adhere to their medication.

\section{WHAT THE STUDY ADDS}

- This study has identified socio-demographic factors that are associated with poor adherence to long term therapies which is useful in formulating interventions aimed at improving adherence to antihypertensive medication.

- Patient's beliefs about medication will inform healthcare providers on areas that need to be clarified when patients have been started on antihypertensive medication in order to encourage adherence.

\section{COMPETING INTERESTS}

The Authors declares no competing interests.

\section{ACKNOWLEDGEMENTS}

The authors wish to thank Nakuru County Referral Hospital, Kenya, Research Review Committee for granting permission to carry out the research in the facility.

\section{REFERENCES}

[1] E. Sabatè, "Adherence to Long-term therapies: Evidence for action World Health Organization". Geneva Switzerland: 2003.

[2] World Health Organization. Hypertension; 2018: Available from: https://www.who.int/gho/ncd/risk_factors/blood_pressure_prevalence text/en/.

[3] G.U.P. Iloh, A.N. Amadi,G.O.P. Okafor, A.O. Ikwadima, F.U. Odu, and E.O. Godswill-Uko, "Adherence to lifestyle modification among adult hypertensive Nigerians with essential Hypertension in a Primary care clinic of a tertiary hospital in a resource poor environment of eastern Nigeria”. Brj Med Res, 4(18), PP.3478-90, 2014.

[4] R. Al-Ramah, "Adherence to medications and associated factors: A cross-sectional study among Palestinian Hypertensive patients." $J$ Epidemiol Glob Health, 5(2), PP.125-132, 2015.

[5] C.D. Kang, P.P. Tsang, V.T. Li, H.H. Wang, K.G. Li, S.M. Griffiths, et al., "Determinants of medication Adherence and Blood pressure control among hypertensive patients in Hong Kong: A cross-sectional study." Int J Cardiol, Vol. 182, PP. 250-257, 2015.

[6] Institute NEH. Thinking Outside the pillbox: A system-wide approach to improving patient medication adherence for chronic disease: New England Healthcare Institute: 2009

[7] H. Leventhal, L.A. Philips, and E. Burns, "The common sense model of Self-Regulation. A Dynamic framework for understanding illness self-management." Journal of Behavioral Medicine, Vol. 39(6), PP. 935-946, 2016

[8] R. Horne, J. Weimann, and M. Hankins, "The Beliefs about Medicine Questionnaire: The development and Evaluation of a New Method of assessing the Cognitive Representation of Medication." Journal of Psychology and Health, Vol, 14(1), PP. 1-24, 1999.

[9] D.E. Morisky , A. Ang, M. Krousel-wood, and H. Ward, "Predictive Validity of a Medication adherence Measure in an out-patient setting." Journal of Clinical Hypertension, Vol. 10(5), PP. 348-354, 2008.

[10] L. Achieng, M.D. Josh, E.N. Ogola, and E. Karari, "Adequacy of Blood Pressure Control and Level of adherence with Antihypertensive Therapy." East African medical Journal, Vol. 10(5), PP. 348-354, 2009.

[11] E. Mutua, N.M. Gitonga, B. Mbuthia, N. Muriuki, J. Cheptum, and T. Maingi, "Level of Blood Pressure Control among Hypertensive patients on follow up in a Regional Referral Hospital in Central in Kenya." Pan African Medical Journal, Vo. 18, PP. 278, 2014.

[12] M. Fernandez-Arias, A. Villaorduna, J. Miranda, F. Diez-Canse, and G.Malaga. "Adherence to Pharmacotherapy and medication related beliefs in Patients with Hypertensive in Lima, Peru." PLosOne. Vol. 9(2), PP. e112875, 2014

[13] S.H.Lo, J.P. Chau, J.M.WOO, D.R.Thompson, and K.C. Choi, "Adherence to antihypertensive medication in older adults with hypertension.” Journal of Cardiovascular Nursing, Vol. 31(4), PP.296303, 2016.

[14] J. Rajpura, and R. Nayak. "Medication adherence in a sample of elderly suffering from hypertension. Evaluating the influence of Illness 
perceptions, Treatment Beliefs, and Illness Burden." Journal of Pharmaceutical management Care. Vol. 20(1), PP 50-65, 2014.

[15] S. Saarti, A. Hajj, L. Jabbour, A. Sarkisa, et al., "Association between Adherence, Treatment Satisfaction and Illness Perception in Hypertensive Patients." Journal of Human Hypertension. Vol. 30(5), PP. 341-345, 2016.

[16] V. Boima, A. Ademola, A. Odusola, F.Agyekum, C. Nwofor, et al., "Factors Associated with Medical Non-adherence among Hypertensive patients in Ghana and Nigeria." International Journal of Hypertension, Vol. 10(1155) PP. 205-716, 2015.

[17] P. Munter, A. Anderson, J. Charleston, Z. Chen, V. Ford, et al., "Hypertension Awareness, Treatment and control in Adults with Chronic Kidney Disease. Results from the chronic Renal Insufficiency Cohort Study.” American Journal of Kidney Disease. Vol. 55(3), PP. 44-51, March 2010.

[18] S. Sontakke, R. Budania, C. Bajait, K. Jaiswal, and S. Pimpalkhute, "Evaluation of Adherence to Therapy in Patients of Chronic Kidney Disease." Indian Journal of Pharmacology, Vol. 47(6), PP. 668-671, Nov, 2015.

[19] E.K. Massey, M. Tielen, M. Laging, D.K. Beck, R. Khemai , et al., "The Role of Goal Cognitions, Illness Perceptions and Treatment Beliefs in Self-Reported Adherence after Kidney Transplantation: A cohort Study." Journal of Psychosomatic Research, Vol. 75(3), PP. 229-34, Sept, 2013.

[20] L. Platt, H. Green and S. Morrissey, "Understanding Adherence in Patients with Coronary Heart Disease: Illness Representation and Readiness to Engage in Healthy Behaviors." Journal of Australian Psychologist. Vol. 49(2), PP. 127-137, 2014.

[21] M.E. Arbabshastan, A. Arbabisarjou, M. Dehghan, S. Iranmanesh, I. Zareban, and S. Pakdel, "Analytical Assessment of Belief about Medicine among Patients with Hypertension. A case study on Patient's referred to Medical Centers." Global Journal of Health Science, Vol. 9(2), PP. 102-105, 2016.

[22] T. Ruppar, F. Dobbles, and S. DeGeest, "Medication Beliefs and antihypertensive Adherence among Older Adults: A Pilot Study." Geriatric Nursing, Vol. 33, PP. 89-95, 2012.
[23] A. Aflaskeir, "Role of illness and Medication Perception on Adherence to Medication in a Group of Iranian Patients' with Type 2 Diabetes.' Journal of Diabetes, Vol. 4(3), PP. 243-7, 2012.

[24] C. Mahler, K. Hermann, R. Horne, S. Janks, W. Haefeli, and J. Szecsenvi, "Patients' Beliefs about medicines in a Primary care setting in Germany." Journal of Education Clinical Practice, Vol. 18(2), PP. 409-413, Apr, 2012.

[25] W.M. Sweileh, S.H. Zyoud, R.J. Nab’al, M. Deleq, M.Enaia, et al., "Influence of Patients' Disease Knowledge and Beliefs about Patients with Type 2 Diabetes Mellitus in Palestine." BMC Public health, Vol. 14(1), PP. 96-98, 2014

[26] M.J. Raniah, M.S. Waleed, E.A. Adham Saed, and H.Z. SA'ed, "Beliefs about Medicine and Self-reported Adherence among Patients with Chronic Illness: A Study in Palestine." Journal of Family Medicine and Primary Care, Vol. 3(3), PP. 224-229, 2014.

[27] F. Mostafavi , A. Najim, G. Sharifirad, and P. Golshiri, "Beliefs about Medicines in Patients with Hypertension: The Instrument Validity and Reliability in Iran.” Mater SocioMed, Vol. 28(4), PP. 298-302, 2016.

[28] T. Yamane. 1967. Statistics, an Introductory Analysis, $2^{\text {nd }}$ Ed., New York: Harper and Row

[29] G. O. Young, "Synthetic structure of industrial plastics," in Plastics, 2nd ed. vol. 3, J. Peters, Ed. New York: McGraw-Hill, 1964, pp. 1564.

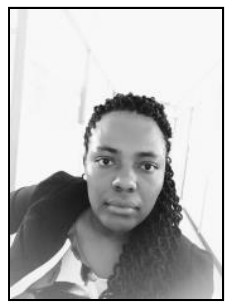

Otenyo Salome Oyiela was born in Kenya on the $4^{\text {th }}$ of July, 1987.

Educational Background:

Phd. Nursing, Masinde Muliro University of Science and Technology, Kenya-On-going.

Msc. Nursing. University of Dundee, Scotland2017.

Bsc. Nursing, University of Eastern Africa Baraton, Kenya- 2010

She is currently working as a lecturer at the department of Nursing- Egerton University Kenya.

Ms. Otenyo Salome Oyiela is a member of the Nurses Association of 